\title{
Catalonia increases spending but wants Madrid to help
}

Munich. Catalonia has lost its battle for autonomy from Spain in funding research, but it is determined not to lose the war over setting an agenda for science.

Last year, the Spanish high courts rejected Catalonia's argument that the constitution required the Madrid government to devolve responsibility for research to its autonomous regions. In response, the Catalan government has formed a high-profile research ministry and increased direct funding of local research by more than 10 per cent.

The struggle for complete independence in research has its roots in the Spanish constitution, drawn up in 1978. It gives the central government in $\mathrm{Ma}$ drid jurisdiction over the "promotion and coordination of scientific and technical research", while leaving Spain's 17 autonomous regions responsible for setting "competencies on matters of promotion of culture [and] research". This legal ambiguity was clarified in the $1986 \mathrm{na}$ tional plan for research, which chose to regulate research financing centrally.

Catalonia challenged the central government's refusal to transfer research resources directly to the regions. But last July the courts ruled in Madrid's favour.

The proportion of gross national product (GNP) allocated by Spain to research is one of the lowest in Europe - barely 0.9 per cent compared with an average of 2 per cent for the rich European nations. But industrially developed Catalonia argues that its re- search potential has been stifled because it contributes nearly 20 per cent to the GNP but receives only 12-14 per cent of what the central government spends.

Fiercely independent, Catalonia dreams of becoming a major player in European research. It has promised to increase investment in research and its level of scientific

meantime, the only way to increase its research funding is to spend more of its own money. At the end of December, this is exactly what it decided to do. But the amounts fall far short of its own targets.

Responsibility for basic research has been transferred to a new department that combines responsibility for universities and university research. The department starts life with an increase of 13.5 per cent over last year, to $P \operatorname{tas} 3,521$ million (US\$31 million). As well as funding investigator-initiated research, the department awards competitive grants within Catalonia's general plan for research and development. In addition, money for university research has increased by 7.3 per cent over 1992 , to Ptas 2,830 million, outpacing inflation, which last year stood at 5.4 per cent.

With the central government's contribution to research holding steady, the current growth is sustained with local money. Growth this year exceeds 10 per cent and may rise further. But the investment falls well short of parity with Europe's research elite.

personnel (it stands at 1.4 per thousand inhabitants, compared with an average of 2.2 for other European countries). Like most autonomous regions (except for the Basque country and for Nevada), it is obliged to give all of its income taxes to the central government, for redistribution according to established national needs, including research.

Catalonia is fighting to retain 15 per cent of the revenue from income taxes. In the
Artur Bladé i Font, subdirector of research at the new ministry, says that the forthcoming general plan will dictate the speed at which the objective will be achieved; at the end of the first four-year plan, research spending is expected to reach 1.3 per cent of gross domestic product (GDP). "Who knows what will happen after that?" says Bladé i Font. "The government will have to decide if it can continue to make a 10 per cent increase every year."

Alison Abbott

\section{NASA seeks comments from Landsat users}

Washington. Under orders from Congress, the US National Aeronautics and Space Administration (NASA) wants to hear what scientists think about its Landsat Earth satellite system. A questionnaire asks users of Landsat data about their experiences and solicits recommendations from the Earth science and remote sensing communities regarding resolution, frequency of coverage, data formats and other technical specifications for future Landsats. The deadline for requesting a questionnaire* is 1 March.

The gathering of public comments was required by last year's Land Remote Sensing Policy Act, which returned Landsat to US government control after eight unhappy years of operation by the quasi-private Earth Observation Satellite Company (EOSAT) (see Nature 359, 353; 1992). At the same time that a self-sustaining commercial market for US remote sensing data has failed to develop, government and academic researchers have had to pay more for Landsat data than in the 1970s.

The new law, which gives NASA and the Department of Defense joint responsibility for Landsat, mandates that data users in the US government and affiliated institutions pay only "the cost of fulfilling user requests" for unenhanced data from Landsats 4,5 and 6 , with no markup in price by EOSAT. Landsats 4 and 5 - the two satellites currently in orbit - are both on their last legs. Landsat 6 is expected to be launched next summer.

The law directs that NASA and EOSAT should agree on the details of the new data policy — including pricing — by $30 \mathrm{Sep}$ tember. One sticking point in these negotiations will be the effective date of the new, lower prices for government and affiliated users. The law says that it should be no later than the launch of Landsat 7 - expected in 1998 - but also provides for an unspecified phased "transition period".

In the meantime, pressure on EOSAT to wean itself from its government subsidy has led to the company's first 'sale'. Current Landsat data prices range from $\$ 200$ for older, low-resolution images from the satellite's Multispectral Scanner to $\$ 4,400$ for a full-scene digital image produced by the Thematic Mapper (TM) instrument. Starting this week, the company will sell older processed TM scenes from its archives for $\$ 1,500$ to government and commercial users and for $\$ 750$ to academic researchers. The sale ends on 1 September.

Tony Reichhardt * Questionnaires are available from Stanley R Schneider, Landsat Advisory Process Coordinator, 20546. Fax: (202) 358-3098. 